\title{
The surface modifications of multi-walled carbon nanotubes for multi-walled carbon nanotube/poly (ether ether ketone) composites
}

\author{
Zongshuang Cao ${ }^{1,2}$, Li Qiu ${ }^{1,3}$, Yongzhen Yang ${ }^{1,2^{*}}$, Yongkang Chen ${ }^{1,4^{*}}$ \\ and Xuguang Liu ${ }^{1,3}$ \\ ${ }^{1}$ Key Laboratory of Interface Science and Engineering in Advanced Materials, \\ Ministry of Education, Taiyuan University of Technology, \\ Taiyuan 030024, China; \\ ${ }^{2}$ Research Center of Advanced Material Science and Technology, Taiyuan University \\ of Technology, Taiyuan 030024, China; \\ ${ }^{3}$ College of Chemistry and Chemical Engineering, Taiyuan University of Technology, \\ Taiyuan 030024, China; \\ ${ }^{4}$ University of Hertfordshire, School of Engineering and Technology, Hatfield, \\ Hertfordshire AL10 9AB, UK
}

\begin{abstract}
The effects of surface modifications of multi-walled carbon nanotubes (MWCNTs) on the morphology, dynamic mechanical and tribological properties of multi-walled carbon nanotube/poly (ether ether ketone) (MWCNT/PEEK) composites have been investigated. MWCNTs were treated with mixed acids to obtain acid-functionalized MWCNTs. Then the acid-functionalized MWCNTs were modified with ethanolamine (named e-MWCNTs). The MWCNT/PEEK composites were prepared by a solution-blending method. A more homogeneous distribution of e-MWCNTs within the composites was found with scanning electron microscopy. Dynamic mechanical analysis demonstrated a clear increase in the storage modulus of e-MWCNT/PEEK composites because of the improved interfacial adhesion strength between

\footnotetext{
* Corresponding author at: Taiyuan University of Technology, 79, West Yingze Street, Taiyuan 030024, China. Tel/Fax: +86-0351-6014138.

E-mail address: yyztyut@126.com; y.k.chen@herts.ac.uk
} 
e-MWCNTs and PEEK. Furthermore, the presence of e-MWCNTs caused an enhancement in the glass transition temperature of the composites. Wear tests have shown that the friction coefficient of e-MWCNT/PEEK composites decreased significantly during the test after the running-in period. This suggests that there is an obvious improvement in tribological properties of e-MWCNT/PEEK composites. Overall, the e-MWCNT/PEEK composites have exhibited improved properties and are promising for their applications in industry.

Keywords: Surface modifications; composites; dynamic mechanical properties; tribological properties.

\section{Introduction}

Poly (ether ether ketone) (PEEK) is a high-performance semicrystalline thermoplastic polymer that displays a unique combination of thermal stability, low flammability, chemical resistance and excellent mechanical properties over a wide temperature range $[1,2]$. This polymer has found a wide application since its commercialization, such as electronics, medicine, tele-communication and transportation industries (automobiles, aircraft and aerospace) [3]. However, it is difficult to use PEEK in pristine form because of its high friction coefficient and stick-slip behavior. Many research efforts have been devoted to a further improvement of the properties of PEEK via an incorporation with fillers, such as carbon fibers, glass fibers $[4,5]$, and nanoparticles [6-8].

Carbon nanotubes (CNTs) have attracted great interest in polymer reinforcement owing to their extremely high Young's modulus, strength and flexibility [9-11]. Achieving a good dispersion of CNTs in a polymer matrix is the key to fabricate composites with enhanced properties. However, this is commonly a difficult task because carbon nanotubes have a strong tendency to gather and form bundles. To improve the dispersibility of CNTs in polymer matrices, some strategies, such as dispersing CNTs in compatibilizing agents [12] or grafting functional groups onto CNTs' surfaces [13], have been employed. Many studies on the functionalization of 
CNTs and the synthesis of carbon nanotube and PEEK (CNT/PEEK) composites have been carried out since the last decade. Diez-Pascual et al. prepared single-walled carbon nanotube and PEEK (SWCNT/PEEK) composites incorporating polysulfones-I [2], polysulfones-II [14] and polyetherimide [15] as compatibilizers separately and investigated the thermal and dynamic mechanical properties of the SWCNT/PEEK composites. Song et al. worked with sandwich-like SWCNT paper/PEEK composites to study their mechanical performance [16]. Rong et al. studied the effect of multi-walled carbon nanotubes (MWCNTs) on the mechanical properties and crystallization behaviour of PEEK [17] and Ogasawara et al. researched the stress-strain behaviour of multi-walled carbon nanotube and PEEK (MWCNT/PEEK) composites [18]. These studies have been focused on the effects of different modified CNTs on morphological, thermal and mechanical performance of CNT/PEEK composites. However, few detailed reports can be found on the effects of MWCNTs' surface modifications on the dynamic mechanical and tribological properties of MWCNT/PEEK composites, which could make MWCNT/PEEK composites more suitable for a wide range of property requirements in applications.

The work reported in this paper was aimed at studying the effects of surface modifications of MWCNTs on compatibility between MWCNTs and PEEK as well as dynamic mechanical and tribological properties of MWCNT/PEEK composites systematically. The MWCNT/PEEK samples at an identical MWCNTs concentration of $4 \%$ were prepared by solution blending in an organic solvent named $\mathrm{N}, \mathrm{N}$-dimethylformamide (DMF). An extensive comparative characterization was carried out in order to evaluate the potential improvement in MWCNTs' dispersibility in PEEK matrix, the morphology, structures, dynamic mechanical and tribological properties of MWCNT/PEEK composites.

\section{Materials and methods}

\subsection{Materials}

PEEK 450G used in this study was provided in granule form by Jilin Zhongyan 
High Performance Engineering Plastic Co., Ltd, China, with physical properties of density of $1.26 \mathrm{~g} / \mathrm{cm}^{3}$ at $25^{\circ} \mathrm{C}$, melting temperature of $343^{\circ} \mathrm{C}$. Parent MWCNTs (p-MWCNTs), provided by Chengdu Institute of Organic Chemistry, China, had outer diameter of $30 \sim 50 \mathrm{~nm}$, inner diameter of 5 12 nm, length of 10 20 $\mu \mathrm{m}$ and purity of 95\%. Ethanolamine of 99\% purity was purchased from Tianjin Fuyu Chemical Co., Ltd, China. N,N-Dicyclohexylcarbodiimide (DCC) of $99.5 \%$ purity was supplied by Aladdin Chemistry Co. Ltd. N,N-Dimethylformamide (DMF) of 99.5\% purity was obtained from Tianjin Bodi Chemical Co., Ltd, China.

\subsection{Surface modifications of MWCNTs}

It is well known that the preparation process of MWCNT/polymer composites is hindered by the poor dispersibility of MWCNTs in polymer and their strong tendency to aggregate and form bundles. In this study, an acidic treatment on MWCNTs in mixed acids was employed to introduce oxygen-containing groups (hydroxyl groups and carboxyl groups) onto the surfaces of MWCNTs for the reactions with some specific functional groups, which could improve the dispersibility of MWCNTs in

PEEK matrix. The purpose of further surface modification of MWCNTs by ethanolamine was to graft functional groups (amino groups) to increase the compatibility between MWCNTs and PEEK.

\subsubsection{Preparation of acid-functionalized MWCNTs}

Acid-functionalized MWCNTs with carboxylic groups were prepared in strong mixing acid. p-MWCNTs ( $3.0 \mathrm{~g}$ ) were treated in $240 \mathrm{~mL}$ of mixing acid of $\mathrm{H}_{2} \mathrm{SO}_{4}$ and $\mathrm{HNO}_{3}(3 / 1, \mathrm{v} / \mathrm{v})$ under sonication at $50^{\circ} \mathrm{C}$ for 2 hours. The supernatant was removed and the sediment was washed by deionized water until neutral. The product was dried in a vacuum oven at $80^{\circ} \mathrm{C}$ for 24 hours and marked as a-MWCNTs in which hydroxyl and carboxyl groups were grafted on the surfaces of MWCNTs [19], as shown in Fig. 1(a).

\subsubsection{Grafting of ethanolamine to MWCNTs}

In this grafting process, $0.6 \mathrm{~g}$ of a-MWCNTs and $0.2 \mathrm{~g}$ of DCC were added into 
$150 \mathrm{ml}$ of anhydrous ethanol and sonicated in an ultrasound bath at $50^{\circ} \mathrm{C}$ for 20 minutes. Subsequently, a solution of anhydrous ethanol $(150 \mathrm{~mL})$ with ethanolamine $(0.6 \mathrm{~mL})$ was added. Then, the solution and a-MWCNTs dispersion were mixed in a flask and the reaction was allowed to proceed under magnetic stirring at $50^{\circ} \mathrm{C}$ for 10 hours. Finally, the reaction mixture was washed with ethanol and water respectively and dried under vacuum at $80^{\circ} \mathrm{C}$ for 24 hours to obtain the product marked as e-MWCNTs, and amino groups were grafted on the surfaces of MWCNTs [19], as shown in Fig. 1(b).

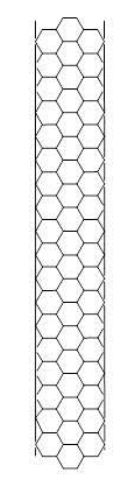

p-MWCNTs

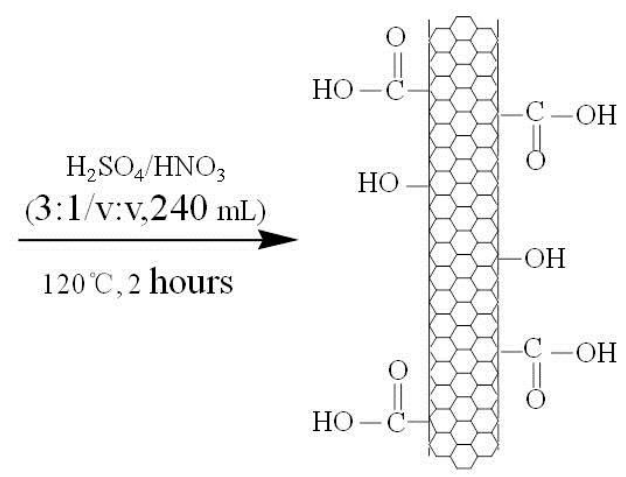

a-MWCNTs

(a) Preparation of a-MWCNTs

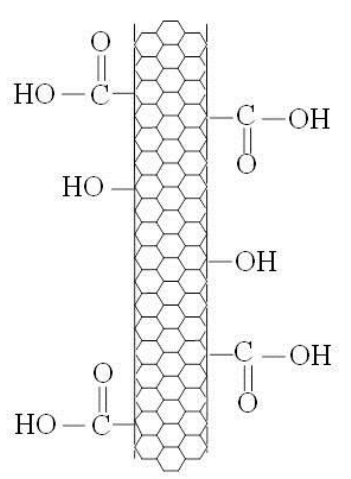

a-MWCNTs

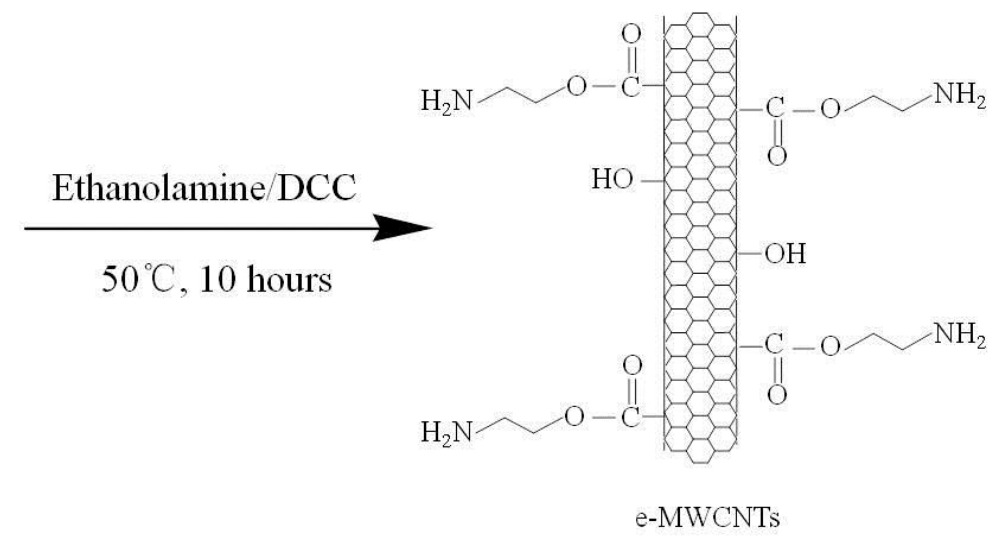

(b) Preparation of e-MWCNTs

Fig.1 The schematic views of principles in surface modification of MWCNTs: preparation of (a)a-MWCNTs and (b) e-MWCNTs.

\subsection{Fabrication of MWCNT/PEEK composites}

In the preparation process of MWCNT/PEEK composites, p-, a- and e-MWCNTs were mixed with PEEK separately. Pure PEEK (1.92 g) was added into $10 \mathrm{~mL}$ of DMF and sonicated for 30 minutes at $30{ }^{\circ} \mathrm{C}$. Then the polymer solution was mixed 
with $0.08 \mathrm{~g}$ of p-, a- and e-MWCNTs, separately. Each mixture was sonicated for 30 minutes at $30^{\circ} \mathrm{C}$ and then each product was added into an aluminum mould. The composites were dried at $60^{\circ} \mathrm{C}$ until a constant weight was achieved.

\subsection{Materials characterization}

\subsubsection{Scanning electron microscopy}

The morphology of the different MWCNTs and MWCNTs/PEEK composites was observed with a JSM-6700F scanning electron microscope (SEM, acceleration voltage: $0.5 \sim 3.0 \mathrm{kV}$, beam intensity: $10^{-13} \sim 2 \times 10^{-9} \mathrm{~A}$, operated at $10 \mathrm{kV}$ ). The samples were coated with gold in an evaporator to avoid charging during electron irradiation.

\subsubsection{Fourier transformation infrared (FTIR) spectroscopy}

The chemical structures of parent and modified MWCNTs were characterized using a TENSOR 27 Fourier transformation infrared (FTIR) spectrometer. Spectra were recorded at a spectral resolution of $1.5 \mathrm{~cm}^{-1}$, and two scans were collected for each sample in the range of 4000 500 $\mathrm{cm}^{-1}$.

\subsubsection{Dynamic mechanical analysis}

The dynamic mechanical properties of the different MWCNT/PEEK composites were studied using a NETZSCH-242E dynamic mechanical analyzer (DMA) at a frequency of $1 \mathrm{~Hz}$ and each sample was tested at least two times to verify the test repeatability of all samples.

\subsubsection{Friction and wear tests}

The tribological properties of the composites were evaluated by a POD 2 Pin-on-disc tester. All the friction and wear tests were carried out in a dry sliding condition at the ambient temperature of $24^{\circ} \mathrm{C}$. Both a linear speed of $0.0295 \mathrm{~m} / \mathrm{s}$ and a contact load of $3.929 \mathrm{~N}$ on the pin were applied in each test for a duration of one hour. The morphology of the worn surfaces of the material samples and the scratching depth on these worn surfaces were observed with a VHX-1000 optical microscope. 


\section{Results and discussion}

\subsection{The sole-dispersibility of MWCNTs}

The morphology of MWCNTs was observed by SEM. Fig. 2 shows SEM micrographs of p-MWCNTs, a-MWCNTs and e-MWCNTs. From Fig. 2(a), it can be seen clearly that p-MWCNTs were accumulated loosely with large tube gaps and each nanotube had a uniform pipe diameter. Fig. 2(b) shows that after the acid treatment, a-MWCNTs became shorter and denser, indicating that carboxyl groups were grafted on the surfaces of nanotubes and the hydrogen bonding formed by carboxyl groups resulted in the agglomeration of the nanotubes [20]. As shown in Fig. 2(c), compared with a-MWCNTs, the sole-dispersibility of e-MWCNTs was obviously improved and the e-MWCNTs showed no agglomeration owing to grafting of amino groups on the surfaces of nanotubes [21].
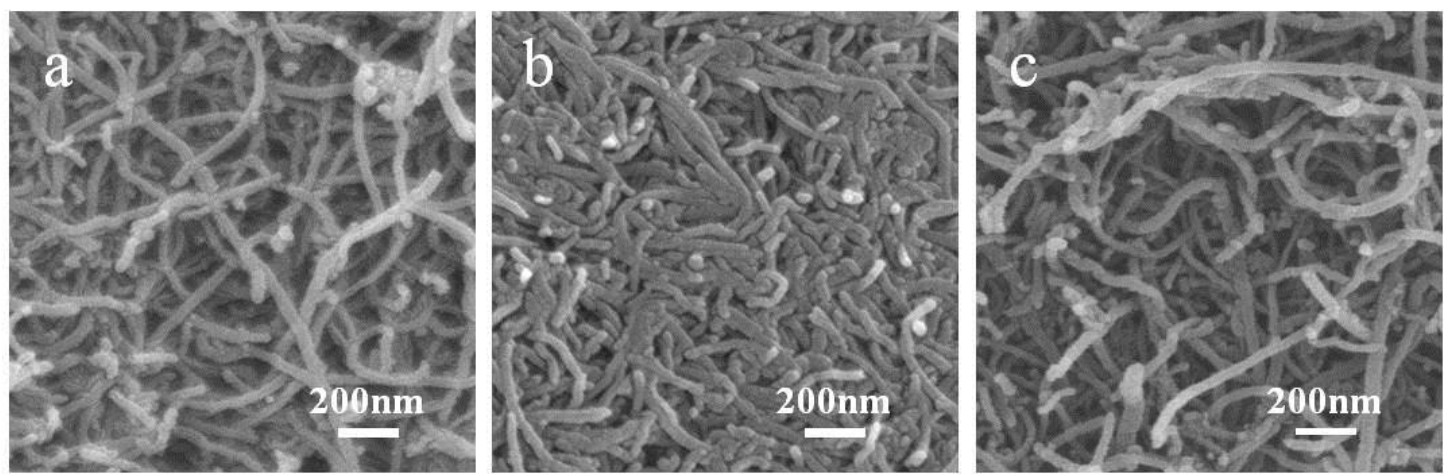

Fig. 2 SEM observations of different MWCNTs: (a) p-MWCNTs, (b) a-MWCNTs, (c) e-MWCNTs.

\subsection{The chemical groups on surfaces of the MWCNTs}

The identification of the chemical groups onto the MWCNT surfaces was conducted through FTIR spectroscopy. The spectra of p-, a- and e-MWCNTs are compared in Fig. 3. It can be seen that p-MWCNTs show no relevant features except the band at $3430 \mathrm{~cm}^{-1}$ and $1560 \mathrm{~cm}^{-1}$. The band at $1560 \mathrm{~cm}^{-1}$ is attributed to the $\mathrm{C}=\mathrm{C}$ stretching of the main structures of the MWCNTs [22] and the band around $3430 \mathrm{~cm}^{-1}$ is the $\mathrm{O}-\mathrm{H}$ stretching owing to the preparation process of p-MWCNTs. Fig. 3 also shows that a-MWCNTs present a broad absorption centred at $3430 \mathrm{~cm}^{-1}$ assigned to the $\mathrm{O}-\mathrm{H}$ stretching of the carboxylic group, and a band at $1640 \mathrm{~cm}^{-1}$ corresponding to 
the $\mathrm{C}=\mathrm{O}$ stretching vibration [13], which has an agreement with the preparation of a-MWCNTs as shown in Fig. 1(a). The C-H stretching vibrations occur around 2920 $\mathrm{cm}^{-1}$ and $2850 \mathrm{~cm}^{-1}$, and the band around $1410 \mathrm{~cm}^{-1}$ is ascribed to $\mathrm{C}-\mathrm{H}$ bending of methylene groups. Regarding the spectra of e-MWCNTs, the band at $3380 \mathrm{~cm}^{-1}$ corresponds to asymmetrical stretching vibrations of N-H group. Therefore, it is suggested that the amino groups $\left(-\mathrm{NH}_{2}\right)$ of ethanolamine have been grafted on the surfaces of MWCNTs, as shown in Fig. 1(b).

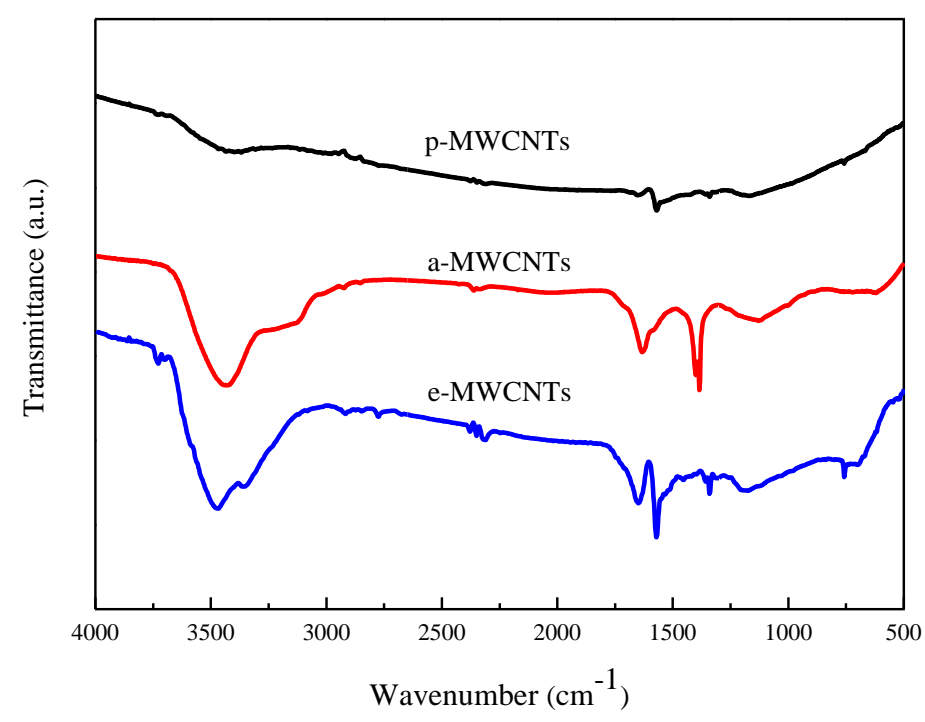

Fig. 3 FTIR spectra of p-MWCNTs, a-MWCNTs and e-MWCNTs.

\subsection{The dispersibility of MWCNTs in PEEK}

SEM was also employed to observe the dispersibility of MWCNTs in PEEK. Achieving a good distribution of carbon nanotubes in PEEK matrix is a commonly difficult task, because p-MWCNTs have a strong tendency to gather and form bundles [2]. Fig. 4 shows a comparison of typical micrographs of p-MWCNT/PEEK, a-MWCNT/PEEK and e-MWCNT/PEEK composites with a concentration of $4 \mathrm{wt} \%$ MWCNTs. In Fig. 4, MWCNTs appeared as bright spots, as indicated by dash arrows. It can be seen in Fig. 4(a) that p-MWCNT/PEEK composites showed an agglomeration of p-MWCNTs, the domain size of the dispersed phase was large and there were small regions where p-MWCNTs agglomeration could be observed as 
marked by a dash circle. As shown in Fig. 4(b), a-MWCNTs were also agglomerated in PEEK matrix but dispersed better in PEEK than p-MWCNTs in PEEK, probably owing to grafting of carboxyl groups $(-\mathrm{COOH})$ on the surfaces of MWCNTs. As shown in Fig. 4(c), e-MWCNT/PEEK displayed an improved dispersion of the reinforcement phase. Therefore, it is suggested that a reaction between amino groups $\left(-\mathrm{NH}_{2}\right)$ on the surfaces of e-MWCNTs shown in Fig. 1(b) and carbonyl groups $(-\mathrm{C}=\mathrm{O})$ of PEEK may yield an interaction between e-MWCNTs and PEEK.
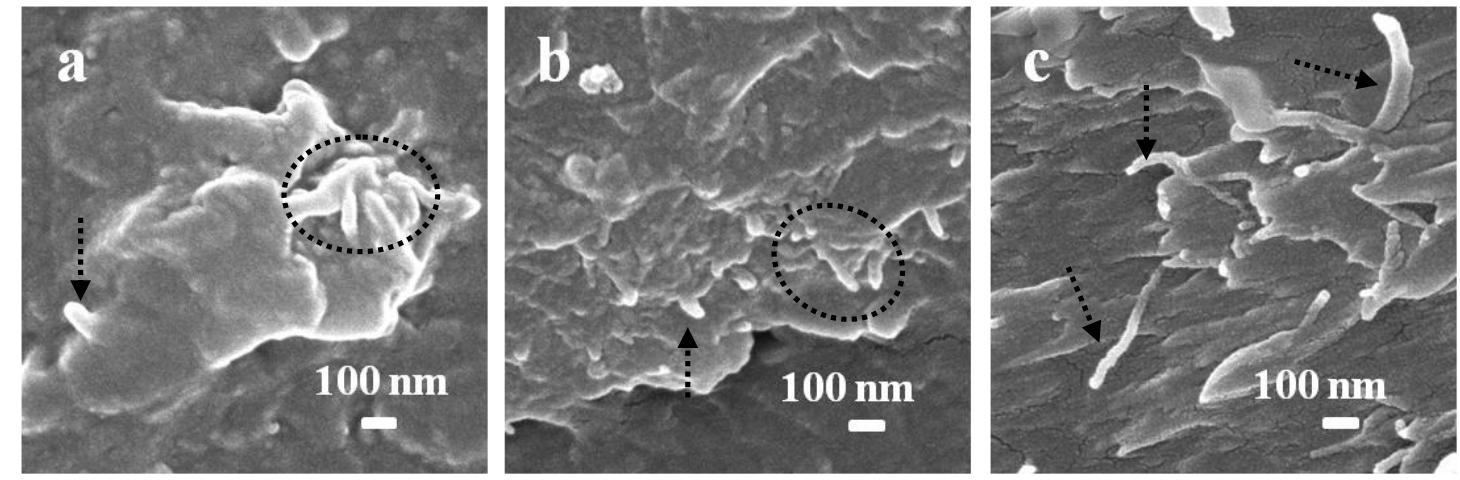

Fig. 4 SEM observations of different MWCNT/PEEK composites: (a) p-MWCNT/PEEK,

(b) a-MWCNT/PEEK, (c) e-MWCNT/PEEK.

In order to calculate the interaction energy of all complexes formed between functional groups on the surfaces of MWCNTs and PEEK, a numerical simulation was carried out with an $\mathrm{Ab}$ initio quantum chemistry package, $\mathrm{Dmol}^{3}$ code. The present level of calculation, density functional theory (GGA-PBE)/double numeric polarized DFT (GGA-PBE)/DNP, was used to optimize the geometries of all compounds, and TS method DFT-D for correction was used for dispersion correction. Interaction energy $(\Delta \mathrm{E})$ was calculated from the following equation:

$$
\triangle E=E_{(M W C N T / P E E K)}-\left(E_{P E E K+} E_{M W C N T S}\right)
$$

The best optimized structures of finite PEEK, a-MWCNTs, e-MWCNTs, a-MWNCT/PEEK and e-MWCNT/PEEK composites are presented in Fig. 5. Table 1 shows a list of calculated interaction energy for all complexes formed between PEEK 
and the functional groups on the surfaces of MWCNTs. It can be seen that a-MWCNT/PEEK had higher binding energy: ( $\triangle$ E(e-MWCNT/PEEK) > $\triangle \mathrm{E}(\mathrm{a}-\mathrm{MWCNT} / \mathrm{PEEK}))$. Accordingly, it can be concluded that the interaction between the $-\mathrm{NH}_{2}$ on surfaces of e-MWCNTs and the $-\mathrm{C}=\mathrm{O}$ of PEEK is much stronger than the interaction between the $-\mathrm{COOH}$ on surfaces of a-MWCNTs and the $-\mathrm{C}=\mathrm{O}$ of PEEK [23].

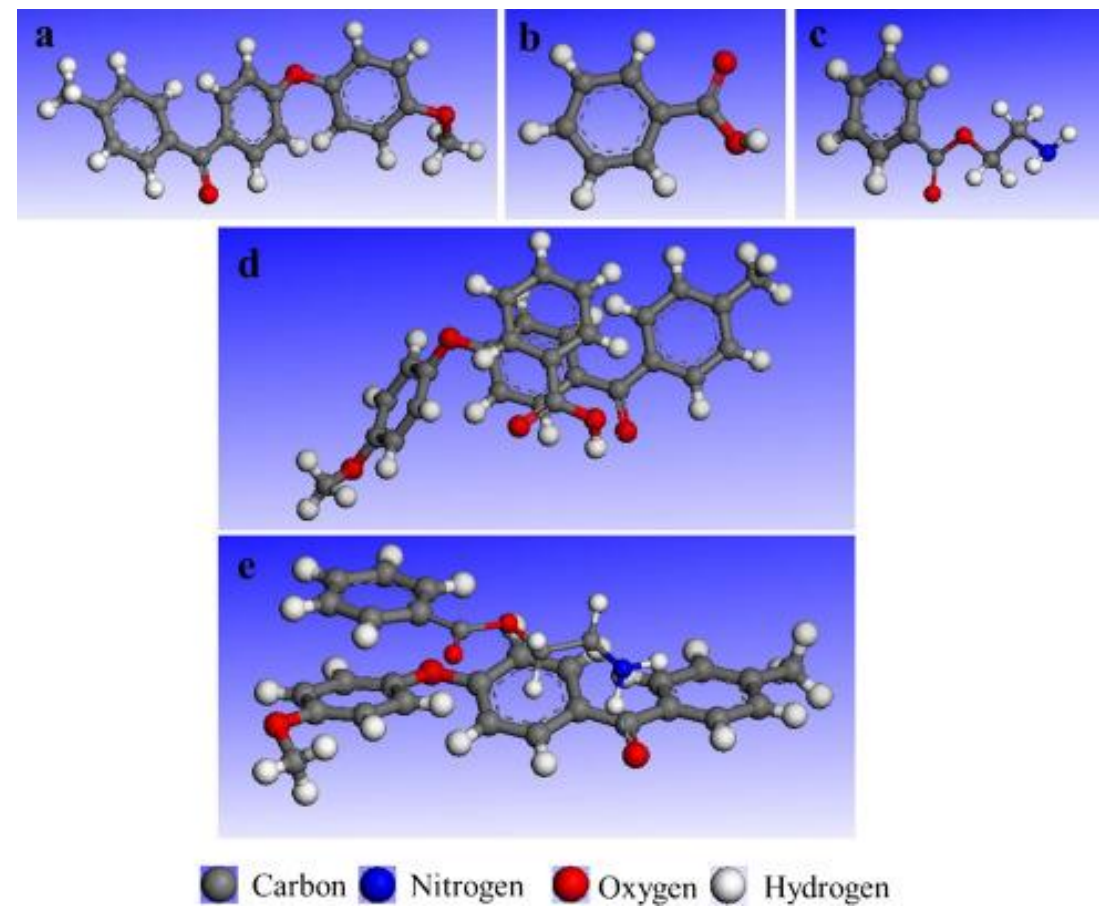

Fig. 5 Optimized structures of finite PEEK and MWCNT/PEEK composites: (a) PEEK, (b) a-MWCNTs, (c) e-MWCNTs, (d) a-MWCNT/PEEK and (e) e-MWCNT/PEEK.

Table 1 Summary of the binding energies of complexs at GGA/PBE (DFT-D correction) level.

\begin{tabular}{|l|l|l|l|}
\hline Molecules & $\boldsymbol{E}(\mathbf{a . u})$ & $\boldsymbol{\Delta E}(\mathbf{a . u})$ & $\Delta \mathbf{E}^{\mathbf{a}}\left(\mathbf{k c a l ~ m o l}^{\mathbf{1}}\right)$ \\
\hline PEEK & -1035.8545997 & - & - \\
\hline a-MWCNTs & -420.494824 & - & - \\
\hline e-MWCNTs & -554.3342676 & - & - \\
\hline a-MWCNT/PEEK & -1456.3448938 & 0.020331 & 12.75777 \\
\hline e-MWCNT/PEEK & -1590.2159633 & 0.027096 & \\
a 1a.u=627.5094kcalmol
\end{tabular}




\subsection{The dynamic mechanical properties of MWCNT/PEEK composites}

The main goal of surface modifications of MWCNTs is to improve the mechanical properties of the MWCNT/PEEK composites. These properties of the composites depend on many factors, such as the compatibility between MWCNTs and PEEK. The effects of surface modifications of MWCNTs on the dynamic mechanical properties of MWCNT/PEEK composites have been investigated by DMA. Fig. 6 shows the temperature dependence of the storage modulus E' (Fig. 6(a)) and $\tan \delta$ (Fig. 6(b)) of pure PEEK and different types of MWCNT/PEEK composites with an identical MWCNTs concentration of $4 \mathrm{wt} \%$ at a frequency of $1 \mathrm{~Hz}$. As can be seen in Fig. 6(a), storage modulus E' decreased slowly and progressively with temperature, showing a very sharp drop in the temperature range between 80 and $100^{\circ} \mathrm{C}$. The fall of storage modulus was attributed to an energy dissipation phenomenon involving cooperative motions of the polymer chains [24]. From Fig. 6(a), it can be seen clearly that the incorporation of MWCNTs induced an obvious increase in storage modulus E' of the matrix at a given temperature below about $80^{\circ} \mathrm{C}$. The increase of storage modulus E' of e-MWCNT/PEEK composites was most pronounced. At $25^{\circ} \mathrm{C}$, the value of storage modulus E' of the e-MWCNTs composites was the highest and approximately $83.78 \%$ higher, while the value of storage modulus E' of p-MWCNT/PEEK and a-MWCNT/PEEK composites was $24.61 \%$ and $42.41 \%$ higher, respectively, than that of pure PEEK, respectively. It appears that such a significant increase in the value of storage modulus E' of the e-MWCNT/PEEK composites corresponds to an improved dispersibility of e-MWCNTs in PEEK as shown in Fig.4. Therefore, the modulus increase of e-MWCNT/PEEK composites should be attributed to the improved interfacial adhesion strength and stress transfer ability between the e-MWCNTs and PEEK [15]. 

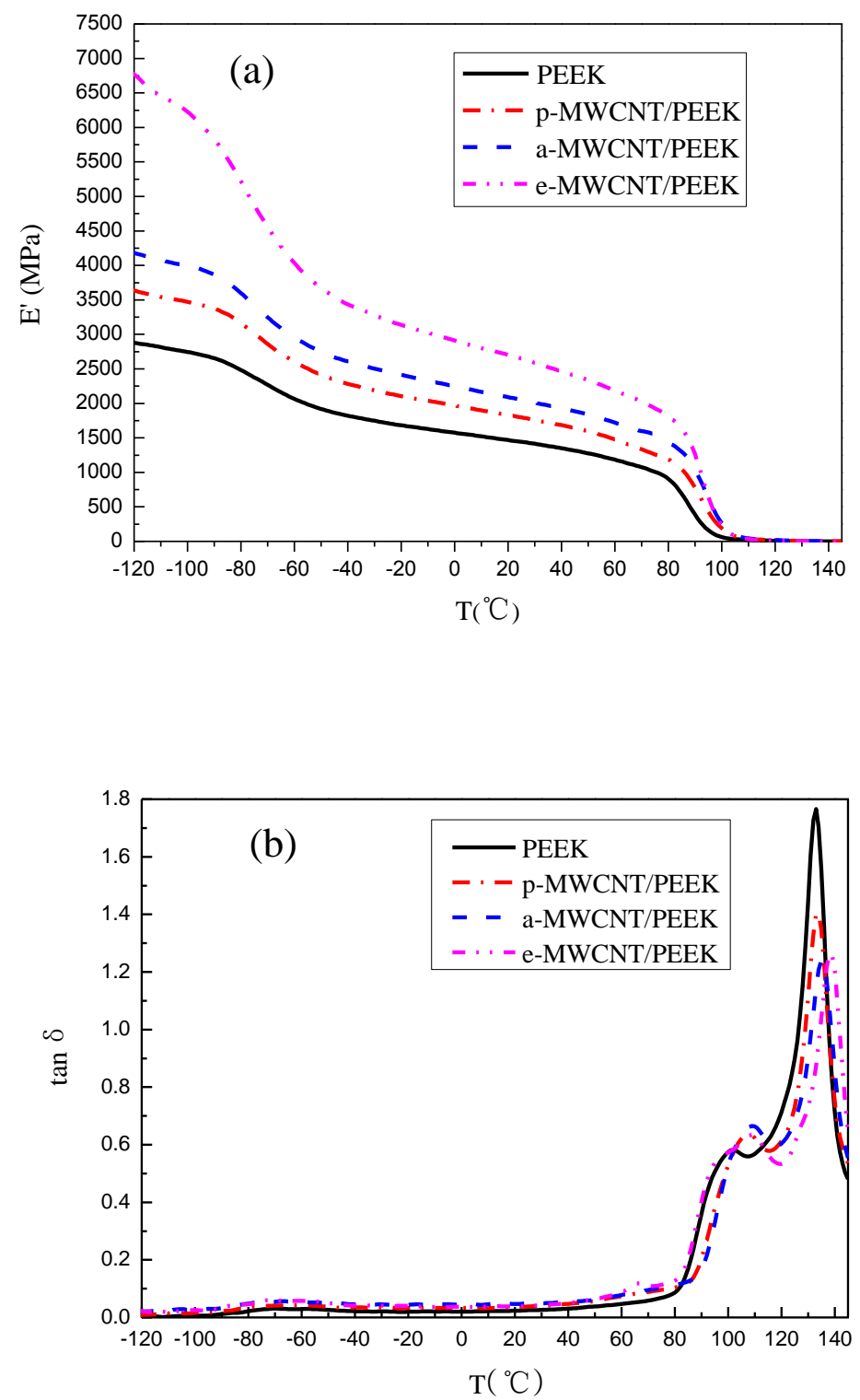

Fig. 6 DMA spectra of pure PEEK and different types of MWCNT/PEEK composites (4\% MWCNTs) at a frequency of $1 \mathrm{~Hz}$ : (a) Storage modulus E' versus temperature; (b) tan $\delta$ versus temperature.

Fig. 6(b) shows tan $\delta$ curves versus temperature of pure PEEK and different types of MWCNT/PEEK composites (4\% MWCNTs) at a frequency of $1 \mathrm{~Hz}$. It can be seen that an increase in glass transition temperature $\left(\mathrm{T}_{\mathrm{g}}\right)$ was observed in all MWCNT/PEEK composites, owing to the strong restrictions on polymer chain mobility caused by the incorporation of MWCNTs. Fig. 6(b) also shows that glass transition temperature $\mathrm{T}_{\mathrm{g}}$ of pure PEEK was $133^{\circ} \mathrm{C}$ and the $\mathrm{T}_{\mathrm{g}}$ of $\mathrm{p}-\mathrm{MWCNT} / \mathrm{PEEK}$, 
a-MWCNT/PEEK and e-MWCNT/PEEK composites was increased by about 1,2 and $7^{\circ} \mathrm{C}$, respectively. The increase of e-MWCNT/PEEK composites' $\mathrm{T}_{\mathrm{g}}$ is considerably higher than that of the others. This phenomenon was probably related to the more homogeneous distribution of e-MWCNTs in PEEK [13]. Moreover, a diminution of the height of $\tan \delta$ peak from MWCNT/PEEK composites was observed because of the strong MWCNT-polymer interactions. The tan $\delta$ peak value of e-MWCNTs was least. It suggests that the interactions between e-MWCNTs and PEEK were stronger than those in p-MWCNT/PEEK and a-MWCNT/PEEK composites.

\subsection{The macro friction and wear behaviours of MWCNT/PEEK composites}

Fig. 7 presents the friction coefficient of pure PEEK and MWCNT/PEEK composites tested at a sliding velocity of $0.0295 \mathrm{~m} / \mathrm{s}$ and normal load of $3.929 \mathrm{~N}$. As shown in Fig. 7, the friction coefficient of a-MWCNT/PEEK was higher than that of pure PEEK, the friction coefficient of p-MWCNT/PEEK became higher than that of pure PEEK after about 2290 seconds during the test. The friction coefficient of e-MWCNT/PEEK composites was the least and reduced by about $12 \%$ compared with that of pure PEEK.

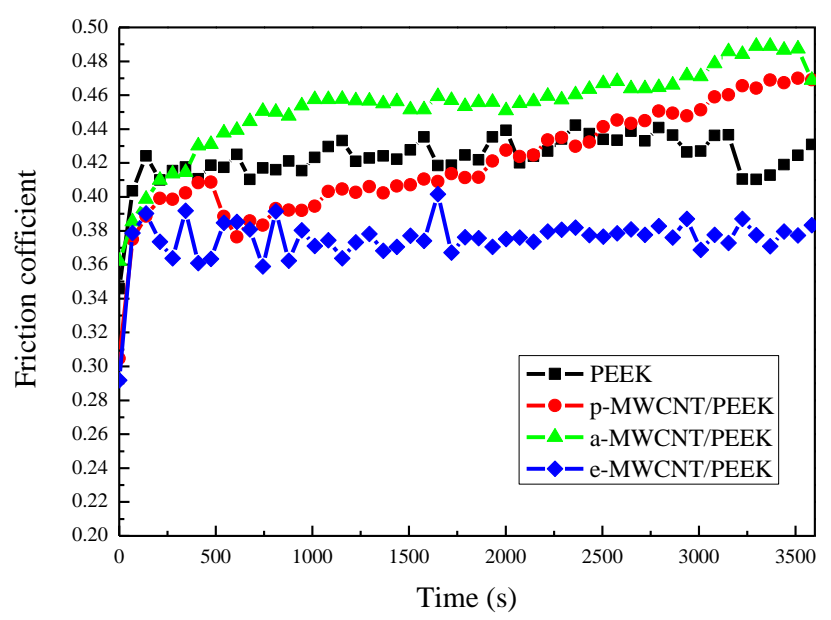

Fig. 7 Friction coefficient versus time of MWCNT/PEEK composites (4\% MWCNTs) at the load of $3.929 \mathrm{~N}$ and sliding velocity of $0.0295 \mathrm{~m} / \mathrm{s}$. 
Fig. 8 shows the morphology of worn surfaces of the material samples (Fig. 8(I)) and the scratching depth (Fig. 8(II)) on these worn surfaces of pure PEEK and MWCNT/PEEK composites. As shown in Figs. 8(I)-(II), the scratching depth on PEEK sample surfaces was the largest and the maximum depth was $95.92 \mu \mathrm{m}$. After adding MWCNTs into PEEK matrix, the scratching depth of MWCNT/PEEK composites was reduced considerablyly. The scratching depth of e-MWCNT/PEEK composites was $18 \mu \mathrm{m}$ and was reduced by about $81 \%$ compared with that of pure PEEK.

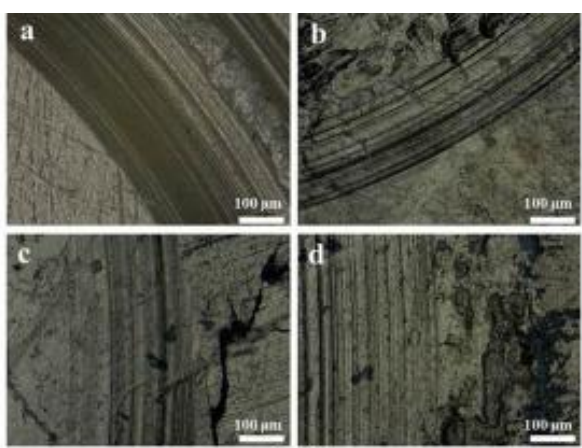

(I)
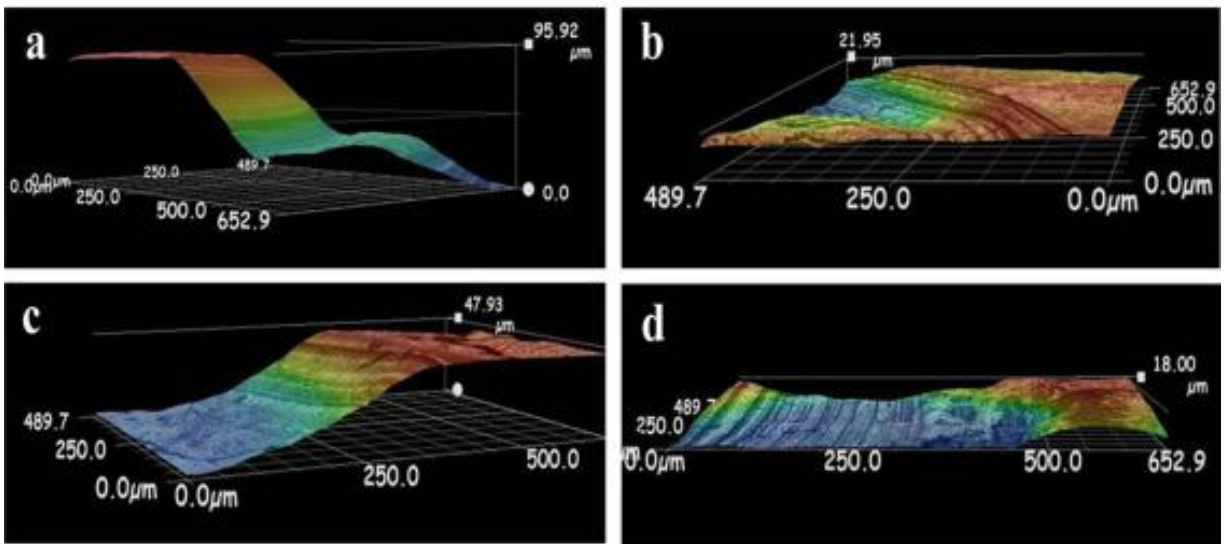

(II)

Fig. 8 The morphology of the wear surfaces (I) and the scratching depth (II) of pure PEEK and MWCNT/PEEK composites: (a) pure PEEK, (b) p-MWCNT/PEEK, (c) a-MWCNT/PEEK and (d) e-MWCNT/PEEK.

Table 2 shows both weight change $(\Delta \mathrm{m})$ and volume change $(\Delta \mathrm{V})$ of pure PEEK and MWCNT/PEEK samples before and after friction tests. $\mathrm{F}_{\mathrm{N}}$ was $3.929 \mathrm{~N}$ and $\mathrm{L}$ was $106.2 \mathrm{~m}$ in the friction tests. The specific wear rate $\left(\mathrm{W}_{\mathrm{s}}\right)$ is calculated by following equation: 


$$
W_{s}=\frac{\Delta m}{\rho F_{N} L} \text { or } \frac{\Delta V}{F_{N} L}\left(\frac{m m^{s}}{N m}\right)
$$

where $\Delta \mathrm{V}$ is a volume change of the test samples over a period of one hour test, $\mathrm{F}_{\mathrm{N}}$ is the normal load and $\mathrm{L}$ is the total sliding distance [25]. It can be seen from Table 2 that the specific wear rate $\mathrm{W}_{\mathrm{s}}$ of a-MWCNT/PEEK composites was the highest in all samples owing to the agglomeration of a-MWCNTs in PEEK matrix. The specific wear rate $\mathrm{W}_{\mathrm{s}}$ of e-MWCNT/PEEK composites was the lowest in all test samples. It suggests that the improved dispersibility of e-MWCNTs in PEEK could reduce the specific wear rate of MWCNT/PEEK composites and improve the tribological properties of MWCNT/PEEK composites significantly.

Table 2 The $\mathrm{W}_{\mathrm{s}}$ of pure PEEK and MWCNT/PEEEK composites obtained from friction tests.

\begin{tabular}{cccc}
\hline Test samples & $\Delta \mathrm{m}(\mathrm{g})$ & $\Delta \mathrm{V}\left(\mathrm{cm}^{3}\right)$ & $\mathrm{W}_{\mathrm{s}}\left(\mathrm{mm}^{3} / \mathrm{Nm}\right)$ \\
\hline Pure PEEK & 0.0008 & 0.001486 & $1.486 \times 10^{-3}$ \\
p-MWCNT/PEEK & 0.0003 & 0.000557 & $5.573 \times 10^{-4}$ \\
a-MWCNT/PEEK & 0.0011 & 0.002043 & $2.044 \times 10^{-3}$ \\
& & & $3.716 \times 10^{-4}$ \\
\hline
\end{tabular}

The SEM images of worn surfaces after testing and cleaning are shown in Fig. 9. It can be seen in Fig. 9(a) that the wear scar of pure PEEK was very deep and wide after its wear test. It illustrates that the surface of pure PEEK had very serious wear and material loss. From Figs. 9(b) and 9(c), it can be seen that the wear scars of p-MWCNT/PEEK and a-MWCNT/PEEK composites were shallower than the wear scar of pure PEEK. The worn surfaces of p-MWCNT/PEEK and a-MWCNT/PEEK composites were smoother than that of pure PEEK. However, p-MWCNTs and a-MWCNTs were not dispersed well within the PEEK matrix and some MWCNTs were exposed to the outside of the PEEK matrix after wear tests. It can be seen clearly in Fig. 9(d) that the worn surface of e-MWCNT/PEEK composites was smoothest, no 
abrasion trace of agglomerates was seen and e-MWCNTs showed the best dispersibility in PEEK matrix.
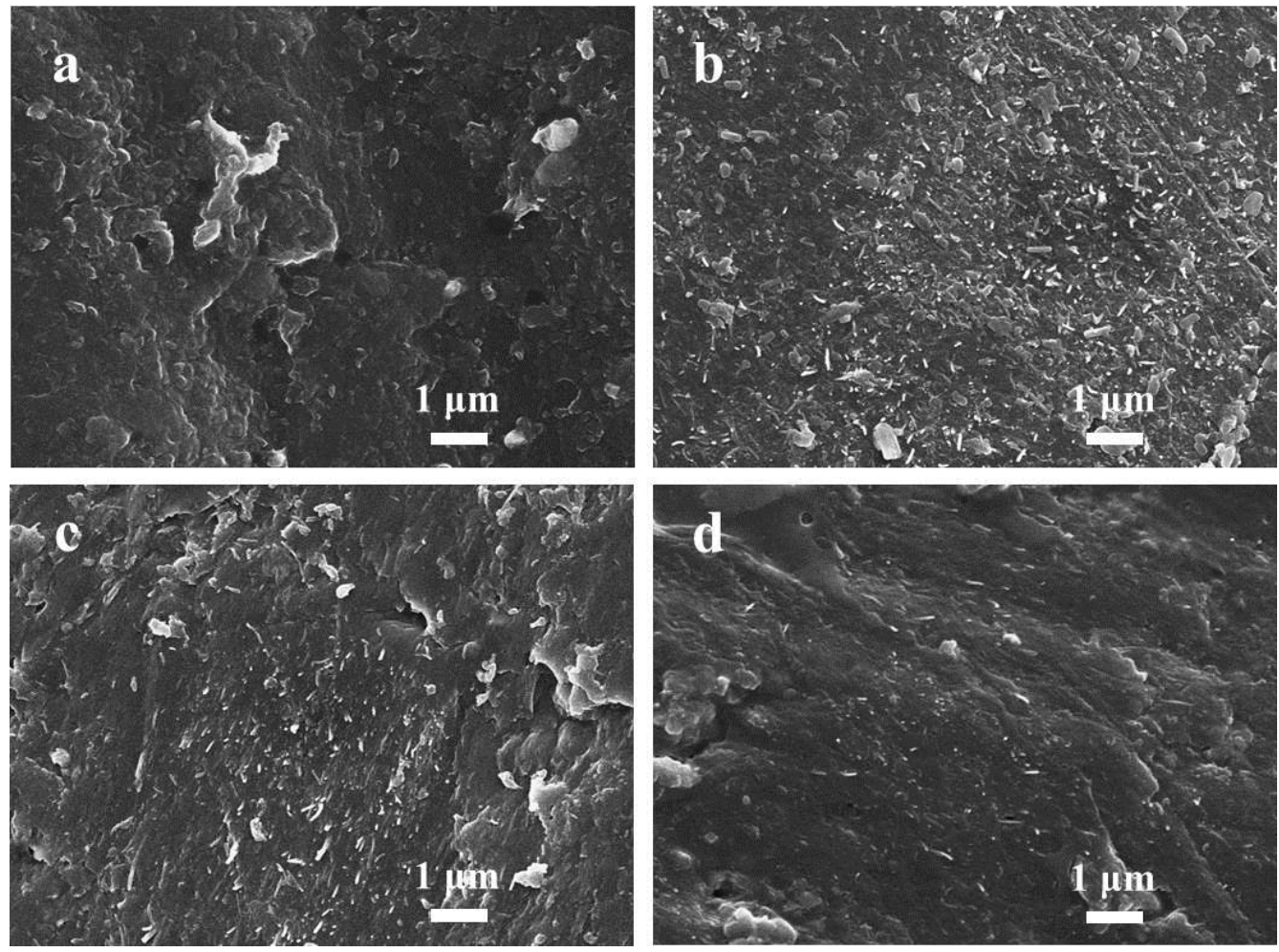

Fig. 9 Typical wear scars of pure PEEK and MWCNT/PEEK composites: (a) pure PEEK, (b) p-MWCNT/PEEK, (c) a-MWCNT/PEEK, (d) e-MWCNT/PEEK.

The testing results shown in Fig. 9 reflect an important material property of MWCNT/PEEK composites that is a self-lubricating capability. Under the identical testing conditions, a reduction of friction coefficient may be resulted from a boundary lubrication behaviour on the contact surfaces of the MWCNT/PEEK composites without any external lubricant [26]. Therefore, it is suggested that this observed lubrication behaviour of the MWCNT/PEEK composites was yielded from materials in contact and may be called as self-lubricating. With such behaviour, the contact surfaces of composites could be protected significantly and the friction coefficient was reduced obviously [27]. It is well known that carbon is a kind of lubricant. However, as shown in Fig. 9, with identical percentage of multi-walled carbon nanotubes, different types of MWCNT/PEEK composites have a different level of self-lubricating capability. The key difference among these three types of 
MWCNT/PEEK composites is a different approach in surface modifications of MWCNTs. As shown in Fig. 4, these three types of MWCNTs have different dispersibility and compatibility in MWCNT/PEEK composites. When p-MWCNTs and a-MWCNTs were agglomerated in PEEK matrix, as shown in Figs. 9(b) and (c), it was difficult for MWCNTs within the composites to be smeared widely and uniformly between the contact surfaces in sliding so that these two types of composites showed a poorer self-lubricating capability. The compatibility between PEEK and p-MWCNTs or a-MWCNTs appears to be much lower than that between e-MWCNTs and PEEK so that it is difficult for the p-MWCNTs and a-MWCNTs to be embedded into the matrix [28], [29], [30] and [31]. The better compatibility and interfacial adhesion [32] between e-MWCNTs and PEEK lead to a better opportunity for MWCNTs within the composites to be smeared on the contact surfaces of e-MWCNT/PEEK composites during the sliding test so that e-MWCNT/PEEK composites have the best self-lubricating capability among pure PEEK and three composites. This is in agreement with an SEM image of the worn surfaces on e-MWCNT/PEEK composites shown in Fig. 9(d). As a result, the friction coefficient of e-MWCNT/PEEK composites was lowest among those of pure PEEK, p-MWCNT/PEEK, a-MWCNT/PEEK and e-MWCNT/PEEK composites.

\section{Conclusions}

In the present work, surface modifications of MWCNTs, and the morphology, dynamic mechanical and tribological properties of MWCNT/PEEK composites have been investigated. Morphological observations show that the sole-dispersibility of MWCNTs and the compatibility between MWCNTs and PEEK were improved significantly when MWCNTs were modified by grafting ethanolamine. DMA measurements indicate that the filling of e-MWCNTs to PEEK leads to an obvious enhancement in the storage modulus of the composites, owing to an improved interfacial adhesion and stress transfer ability between e-MWCNTs and PEEK matrix. Moreover, an increase in the glass transition temperatures of the composites is 
produced because of the chain motion restriction imposed by the strong interfacial interactions between MWCNTs and PEEK matrix. The sliding tests show that the tribological properties of e-MWCNT/PEEK composites were better than pure PEEK, p-MWCNT/PEEK composites and a-MWCNT/PEEK composites although all three MWCNT/PEEK composites have self-lubricating capabilities. In particular, e-MWCNT/PEEK composites have the best self-lubricating capability due to dispersibility of MWCNTs in PEEK matrix and the compatibility between MWCNTs and PEEK. This study sets the way towards the choice of proper MWCNTs' modification routes to enhance specific properties of MWCNT/PEEK composites.

\section{Acknowledgement}

The authors acknowledge financial support from National Natural Science Foundation of China (21176169), Shanxi Provincial Key Innovative Research Team in Science and Technology (2012041011), International Science \& Technology Cooperation Program of China (2012DFR50460) and Research Project Supported by Shanxi Scholarship Council of China (2012-038), and Changjiang Scholar and Innovative Research Team in University (IRT0972).

\section{References}

[1] P. Cebe, S.Y. Chung, S.D. Hong, Effect of thermal history on mechanical properties of poly(ether ether ketone) below the glass transition temperature, J. Appl. Polym. Sci. 33 (1987) 487-503.

[2] A.M. Diez-Pascual, M. Naffakh, J.M. Gonzalez-Dominguez, A. Anson, Y. Martinez-Rubi, M.T. Martinez, B. Simard, M.A. Gomez, High performance PEEK/carbon nanotube composites compatibilized with polysulfones-I Structure and thermal properties, Carbon. 48 (2010) 3485-3499.

[3] O.B. Searle, R.H. Pfeiffer, Victrex ${ }^{\circledR}$ poly (ethersulfone) (PES) and Victrex® poly (ether ether ketone) (PEEK), Polym. Eng. Sci. 25 (1985) 474-476.

[4] M.F. Talbott, G.S. Springer, L.A. Berglund, The effect of crystallinity on the mechanical 
properties of PEEK polymer and graphite fiber reinforced PEEK, J Compos Mater. 21 (1987) 1056-1081.

[5] J.R. Sarasua, P.M. Remiro, J. Pouyet, The mechanical behaviour of PEEK short fibre composites, J Mater Sci. 30 (1995) 3501-3508.

[6] J. Sandler, A.H. Windle, P. Werner, V. Altstadt, M.V. Es, M.S.P. Shaffer, Carbon-nanofibre-reinforced poly (ether ether ketone) fibres, J Mater Sci. 38 (2003) $2135-2141$

[7] P. Werner, R. Verdejio, F. Wollecke, V. Altstadt, J.K.W. Sandler, M.S.P. Shaffer, Carbon nanofibers allow foaming of semicrystalline poly (ether ether ketone), Adv Mater. 17 (2005) 2864-2869.

[8] R.K. Goyal, A.N. Tiwari, Y.S. Negi, High performance nanocomposites for tribological applications: preparation and characterization, Mater Sci Eng A. 486 (2008) 602-610.

[9] M. Alishahi, S.M. Monirvaghefi, A. Saatchi, S.M. Hosseini, The effect of carbon nanotubes on the corrosion and tribological behavior of electroless Ni-P-CNT composite coating, Appl. Surf. Sci. 258 (2012) 2439-2446.

[10] J.N. Coleman, U. Khan, W.J. Blau, Y.K. Gun'ko, Small but strong: a review of the mechanical properties of carbon nanotube-polymer composites, Carbon. 44 (2006) 1624-1652.

[11] J.M. Park, G.Y. Gu, Z.J. Wang, D.J. Kwon, K.L. Devries, Interfacial durability and electrical properties of CNT or ITO/PVDF nanocomposites for self-sensor and micro actuator applications, Appl. Surf. Sci. 287 (2013) 75-83.

[12] S.S. Bafna, T. Sun, D.G. Baird, The role of partial miscibility on the properties of blends of a polyetherimide and two liquid crystalline polymers, Polymer. 34 (1993) 708-715.

[13] A.M. Diez-Pascual, M. Naffakh, Grafting of an aminated poly (phenylene sulphide) derivative to functionalized single-walled carbon nanotubes, Carbon. 50 (2012) 857-868.

[14] A.M. Diez-Pascual, M. Naffakh, J.M. Gonzalez-Dominguez, A. Anson, Y. Martinez-Rubi, M.T. Martinez, B. Simard, High performance PEEK/carbon nanotubes composites compatibilized with polysulfones-II. Mechanical and electrical properties, Carbon. 48 (2010) $3500-3511$

[15] A.M. Diez-Pascual, M. Naffakh, M.A. Gomez, C. Marco, G. Ellis, J.M. Gonzalez-Dominguez, A. Anson, M.T. Martinez, Y. Martinez-Rubi, B. Simard, B. Ashrafi, The influence of a 
compatibilizer on the thermal and dynamic mechanical properties of PEEK/carbon nanotube composites, Nanotechnology. 20 (2009) 1-13.

[16] L. Song, H. Zhang, Z. Zhang, S.S. Xie, Processing and performance improvements of SWNT paper reinforced PEEK nanocomposites, Compos. Part A: Appl. Sci. 38 (2007) 388-392.

[17] C.R. Rong, G. Ma, S.L. Zhang, L. Song, Z. Chen, G.B. Wang, P.M. Ajayan, Effect of carbon nanotubes on the mechanical properties and crystallization behavior of poly (ether ether ketone), Compos. Sci. Technol. 70 (2010) 380-386.

[18] T. Ogasawara, T. Tsuda, N. Takeda, Stress-strain behavior of multi-walled carbon nanotube/PEEK composites, Compos. Sci. Technol. 71 (2011) 73-78.

[19] Z.S. Cao, L. Qiu, Y.Z. Yang, Y.K. Chen, X.G. Liu, The effects of surface modifications of multiwalled carbon nanotubes on their dispersibility in different solvents and poly (ether ether ketone), J. Mater. Res. 22 (2014) 2625-2633.

[20] J. Ming, Y.Q. Wu, Y.C. Yu, F.Y. Zhao, Steaming multiwalled carbon nanotubes via acid vapour for controllable nanoengineering and the fabrication of carbon nanoflutes, Chem. Commun. 47 (2011) 5223-5225.

[21] Y. Sun, S.R. Wilson, D.I. Schuster, High dissolution and strong light emission of carbon nanotubes in aromatic amine solvents, J. Am. Chem. Soc. 123 (2001) 5348-5349.

[22] J. Zhang, H.L. Zou, Q. Qing, Y.L. Yang, Q.W. Li, Z.F. Liu, X.Y. Guo, Z.L. Du, Effect of chemical oxidation on the structure of single-walled carbon nanotubes, J. Phys. Chem. B. 107 (2003) 3712-3718.

[23] M. Michael, R. Emmanuel, N.S. Gil, A density functional theory-based investigation of the functionalization density dependence of the solubility of single-walled carbon nanotubes, J. Sci. Eng. Res. 3 (2012) 2229-5518.

[24] S. Kumar, T. Rath, R.N. Mahaling, C.S. Reddy, C.K. Das, K.N. Pandey, R.B. Srivastava, S.B. Yadaw, Study on mechanical, morphological and electrical properties of carbon nanofiber/polyetherimide composites, Mater. Sci. Eng. B. 141 (2007) 61-70.

[25] C. Lhymn, Effect of normal load on the specific wear rate of fibrous composites, Wear. 120 (1987) 1-27.

[26] L. Qiu, Y.K. Chen, Y.Z. Yang, L.H. Xu, X.G. Liu, A study of surface modification of carbon nanotubes on the properties of polyamide 66/multiwalled carbon nanotube composites, J. 
Nanomater. 2013 (2013) 1-8.

[27] Y.K. Chen, S.N. Kukureka, C.J. Hooke, The wear and friction of short glass-fibre-reinforced polymer composites in unlubricated rolling-sliding contact, J. Mater. Sci. 31 (1996) 5643-5649.

[28] A. Molazemhosseini, H, Tourani, A. Khavandi, B.E. Yekta, Tribological performance of PEEK based hybrid composites reinforced with short carbon fibers and nano-silica, Wear. 303 (2013) 397-404.

[29] G. Theiler, T. Gradt, Friction and wear of PEEK composites in vacuum environment, Wear. 269 (2010) 278-284.

[30] R. Schroeder, F.W. Torres, C. Binder, A.N. Klein, J.D.B. de Mello, Failure mode in sliding wear of PEEK based composites, Wear. 301 (2013) 717-726.

[31] S.F. E, L. Shi, Z. Guo, Tribological properties of self-assembled gold nanoparticles on silicon with polydopamine as the adhesion layer, Appl. Surf. Sci. 292 (2014) 750-755. 